\title{
Group III Metabotropic Glutamate Receptor-Mediated Modulation of the Striatopallidal Synapse
}

\author{
Ornella Valenti, Michael J. Marino, Marion Wittmann, Edward Lis, Anthony G. DiLella, Gene G. Kinney, and \\ P. Jeffrey Conn \\ Department of Neuroscience, Merck Research Laboratories, West Point, Pennsylvania 19486
}

The globus pallidus (GP) is a key GABAergic nucleus in the basal ganglia (BG). The predominant input to the GP is an inhibitory striatal projection that forms the first synapse in the indirect pathway. The GP GABAergic neurons project to the subthalamic nucleus, providing an inhibitory control of these glutamatergic cells. Given its place within the BG circuit, it is not surprising that alterations in GP firing pattern are postulated to play a role in both normal and pathological motor behavior. Because the inhibitory striatal input to the GP may play an important role in shaping these firing patterns, we set out to determine the role that the group III metabotropic glutamate receptors (GluRs) play in modulating transmission at the striatopallidal synapse. In rat midbrain slices, electrical stimulation of the striatum evoked $\mathrm{GABA}_{\mathrm{A}}$-mediated IPSCs recorded in all three types of GP neurons. The group III mGluR-selective agonist L- $(+)-2-$ amino-4-phosphonobutyric acid (L-AP4) inhibited these IPSCs through a presynaptic mechanism of action. L-AP4 exhibited high potency and a pharmacological profile consistent with mediation by mGluR4. Furthermore, the effect of $\mathrm{L}$-AP4 on striatopallidal transmission was absent in mGluR4 knock-out mice, providing convincing evidence that mGluR4 mediates this effect. The finding that mGluR4 may selectively modulate striatopallidal transmission raises the interesting possibility that activation of mGluR4 could decrease the excessive inhibition of the GP that has been postulated to occur in Parkinson's disease. Consistent with this, we find that intracerebroventricular injections of L-AP4 produce therapeutic benefit in both acute and chronic rodent models of Parkinson's disease.

Key words: basal ganglia; globus pallidus; metabotropic glutamate receptor; mGluR4; Parkinson's disease; synaptic transmission

\section{Introduction}

The basal ganglia (BG) are an interconnected group of subcortical nuclei involved in the control of motor behavior. The primary input nucleus of the BG is the striatum, and the primary output nuclei are the substantia nigra pars reticulata $(\mathrm{SNr})$ and the internal globus pallidus (entopeduncular nucleus in nonprimates). The striatum projects to these output nuclei both directly, providing an inhibitory GABAergic input, and indirectly, through the external globus pallidus [GPe; globus pallidus (GP) in non-primates] and the subthalamic nucleus (STN). The STN provides excitatory glutamatergic input to the SNr. A balance between this inhibition and excitation of the output nuclei is believed to be critical for motor control, and disruptions in this balance are believed to underlie various movement disorders (Wichmann and DeLong, 1997, 1998).

A growing number of studies suggest that the GP plays a key role in the pathophysiology of Parkinson's disease (PD). The inhibitory GABAergic synapse between the striatal medium spiny neurons and the GP GABAergic output neurons represents the

Received Jan. 9, 2003; revised June 16, 2003; accepted June 23, 2003.

This work was supported by Merck Research Laboratories. P.J.C. is supported by grants from the National Institutes of Health, National Institute of Neurological Disorders and Stroke, and National Institute of Mental Health. O.V. thanks the Postdoctoral Program in Preclinical and Clinical Pharmacology, University of Catania.

Correspondence should be addressed to Michael J. Marino, Merck Research Laboratories, Merck \& Company, Inc., 770 Sumneytown Pike, P. 0. Box 4, WP 46-200,West Point, PA 19486-0004.E-mail: michael_marino@merck.com.

P. J. Conn's present address: Department of Pharmacology, Vanderbilt University Medical Center, Nashville, TN 37232.

Copyright $\odot 2003$ Society for Neuroscience $\quad$ 0270-6474/03/237218-09\$15.00/0 first synapse in the indirect pathway. The role of the GP in normal motor behavior is underscored by studies in normal primates demonstrating that the firing rate of the GPe is correlated with movement (Georgopoulos et al., 1983; Nambu et al., 1990; Mink and Thach, 1991). Furthermore, recordings from Parkinsonian nonhuman primates reveal a marked increase in rhythmic oscillatory spike discharge in the GPe (Nini et al., 1995; Bergman et al., 1998; Raz et al., 2000). Consistent with this, recordings from human Parkinson's patients reveal similar abnormal firing patterns that appear to correlate with symptom severity and drug treatment (Lozano et al., 1996; El Deredy et al., 2000; Magnin et al., 2000; Brown et al., 2001). The effects of this altered firing pattern on motor behavior may be caused by a disruption in the inhibitory control that the GP exerts on the STN (Wichmann and DeLong, 1997, 1998). The resultant increased activity of the STN leads to a pathological increase in BG output that may underlie many of the motor symptoms of PD.

Several studies in rodent models lend support to the hypothesis that increased GABAergic input may underlie alterations in GP firing patterns. An increase in GABA concentrations in the GP has been demonstrated to have an akinetic effect (Pycock et al., 1976). Furthermore, the $\mathrm{GABA}_{\mathrm{A}}$ antagonist bicuculline produces an antiparkinsonian effect when injected into the GP (Maneuf et al., 1994). These studies suggest that any manipulation that decreases striatopallidal transmission may provide a palliative benefit for the treatment of PD. This potential therapeutic benefit is further underscored by the recent studies suggesting 
antiparkinsonian actions of A2a adenosine receptor antagonists both in animal models (Grondin et al., 1999; Shiozaki et al., 1999; Kanda et al., 2000; Koga et al., 2000) and in human clinical trials (Sherzai et al., 2002; Hubble and Hauser, 2002). A2a antagonists act, at least in part, by decreasing transmission at the striatopallidal synapse (Shindou et al., 2001). Therefore, directly decreasing transmission at this synapse, possibly through the activation of a presynaptic G-protein-coupled receptor, may provide a novel approach for the treatment of PD.

On the basis of their anatomical distribution and functional roles, the metabotropic glutamate receptors (mGluRs) represent an attractive target for the modulation of information flow through the BG (for review, see Rouse et al., 2000; Marino et al., 2002a). The mGluRs are a family of eight G-protein-coupled receptors that are divided into three groups on the basis of sequence homology, G-protein specificity, and pharmacology. The group III mGluRs (mGluR4, -6, -7, and -8) are often found presynaptically localized at both glutamatergic and GABAergic synapses. Activation of these receptors usually produces a presynaptically mediated inhibition of transmission (for review, see Schoepp, 2001). Of the group III mGluRs, mGluR4 has a particularly interesting pattern of distribution in the BG. Previous studies have found high levels of mGluR4 mRNA expression in the striatum (Testa et al., 1994). In addition, high levels of mGluR4 immunoreactivity are present in the GP, whereas more sparse staining is observed in the substantia nigra, the other main target of the striatum (Bradley et al., 1999; Corti et al., 2002). This high level of localization to the GP suggests that selective activation of mGluR4 might produce a decrease in transmission at the striatopallidal synapse.

Here we present evidence for a group III mGluR-mediated inhibition of transmission at the striatopallidal synapse. This effect is presynaptically mediated, has a pharmacology consistent with activation of a group III mGluR, and is absent in mGluR4deficient mice. Taken together these findings suggest that activation of mGluR4 could provide a possible palliative benefit for PD patients. Consistent with this, we have found that intracerebroventricular injection of the group III mGluR agonist L-AP4 has marked antiparkinsonian actions in both acute and chronic rodent models of PD.

\section{Materials and Methods}

\section{Compounds}

(-)Bicuculline methobromide (bicuculline), 6-cyano-7-nitroquinoxaline2,3-dione (CNQX), (2S)-3-[[(1S)-1-(3,4-ichlorophenyl)ethyl]amino-2hydroxypropyl]phosphinic acid (CGP55845), ( $R, S)$ - $\alpha$-cyclopropyl-4phosphonophenylglycine (CPPG), D(-)-2 amino-5-phosphonopentanoic acid (D-AP5), (S)-3,4-dicarboxyphenylglycine [( $S$-3,4-DCPG], and (2S)2-amino-2-[(1S,2S)-2-carboxycycloprop-1-yl]-3-(xanth-9-yl) propanoic acid (LY341495) were obtained from Tocris (Ballwin, MO). L-(+)-2Amino-4-phosphonobutyric acid (L-AP4) was obtained from Alexis/Qbiogene (Carlsbad, CA). All other materials were obtained from Sigma (St. Louis, MO).

\section{Animals}

All animals used in these studies were cared for in accordance with the Guide for the Care and Use of Laboratory Animals. The Merck Research Laboratories institutional animal care and use committee approved all studies described in this paper, and experimental protocols were in accordance with all applicable guidelines regarding the care and use of animals. Animals were housed in an Association for Assessment and Accreditation of Laboratory Animal Care International approved facility with ad libitum access to food and water.

\section{Slice preparation}

All electrophysiology experiments were performed on slices from either 26- to 30-d-old Sprague Dawley rats (Taconic, Germantown, NY) or 5-week-old mice. mGluR4 knock-out mice (Gprcld) (Pekhletski et al., 1996) and control 129X1/SvJ mice were obtained from The Jackson Laboratory (Bar Harbor, ME). Animals were killed by decapitation, and brains were removed rapidly and submerged in an ice-cold choline replacement solution containing (in $\mathrm{mm}$ ): 126 choline chloride, $2.5 \mathrm{KCl}$, $1.2 \mathrm{NaH}_{2} \mathrm{PO}_{4}, 1.3 \mathrm{MgCl}_{2}, 8 \mathrm{MgSO}_{4}, 10$ glucose, and $26 \mathrm{NaHCO}_{3}$, equilibrated with $95 \% \mathrm{O}_{2} / 5 \% \mathrm{CO}_{2}$ (Cooper and Stanford, 2001). The brain was glued to the chuck of a vibrating blade microtome (Leica Microsystems, Nussloch, Germany), and parasagittal slices (300 $\mu \mathrm{m}$ thick) were obtained. Slices were transferred immediately to a holding chamber containing normal artificial CSF (ACSF) (in mM): $124 \mathrm{NaCl}, 2.5 \mathrm{KCl}, 1.3$ $\mathrm{MgSO}_{4}, 1.0 \mathrm{NaH}_{2} \mathrm{PO}_{4}, 2 \mathrm{CaCl}_{2}, 20$ glucose, and $26 \mathrm{NaHCO}_{3}$, equilibrated with $95 \% \mathrm{O}_{2} / 5 \% \mathrm{CO}_{2}$ that was maintained at $32^{\circ} \mathrm{C}$. After $20 \mathrm{~min}$ at $32^{\circ} \mathrm{C}$, the temperature in the holding chamber was allowed to decrease gradually to room temperature. In all experiments, $5 \mu \mathrm{m}$ glutathione, 500 $\mu \mathrm{M}$ pyruvate, and $250 \mu \mathrm{M}$ kynurenic acid were included in the choline chloride buffer and in the holding chamber ACSF.

\section{Electrophysiology}

Whole-cell patch-clamp recordings were obtained as described previously (Marino et al., 2001). During recording, slices were maintained fully submerged on the stage of a brain slice chamber at $32^{\circ} \mathrm{C}$ and perfused continuously with equilibrated ACSF ( $2-3 \mathrm{ml} / \mathrm{min}$ ). Neurons were visualized using a differential interference contrast microscope and an infrared video system. Patch electrodes were pulled from borosilicate glass on a two-stage puller and had resistances in the range of 3 to $7 \mathrm{M} \Omega$ when filled with internal solution. For recording evoked IPSCs, the internal solution consisted of (in $\mathrm{mm}$ ): 125 potassium gluconate, $4 \mathrm{NaCl}, 6$ $\mathrm{NaH}_{2} \mathrm{PO}_{4}, 1 \mathrm{CaCl}_{2}, 2 \mathrm{MgSO}_{4}, 10$ BAPTA-tetrapotassium salt, $10 \mathrm{HEPES}$, 2 Mg-ATP, $0.3 \mathrm{Na}_{2}$-GTP. All recordings were done using HEKA EPC9 patch clamp amplifiers (HEKA Elektronik, Lambrecht/Pfalz, Germany)

IPSCs were evoked in the presence of blockers of AMPA $(20 \mu \mathrm{M}$ CNQX), NMDA (25 $\mu \mathrm{M}$ D-AP5), and GABA $(100 \mathrm{~nm}$ CPG 55845) receptors. Bipolar tungsten stimulation electrodes were placed in the striatum near the border between cortex and striatum at a point just below the forceps minor. All recordings were made from the more medial extent of the GP in slices corresponding to the Paxinos and Watson rat brain atlas (Paxinos and Watson, 1998, their Figures 84-86). The recording site was restricted to the more dorsal half of the GP and was chosen by following the dark striations from the site of stimulation to the point where they terminate in the GP. This electrode configuration was determined empirically to give a high probability of eliciting an IPSC that was sensitive to the D2 agonist quinpirole (see below). It should be noted that in studies from younger (14-25 d old) rats we observed a much lower probability of evoking IPSCs and found it necessary to move the stimulating electrodes much closer to the GP. Interestingly, under these conditions, the evoked IPSC was not affected by application of quinpirole. Therefore, we only used animals $26 \mathrm{~d}$ and older for these studies. IPSCs were evoked by single pulses that ranged from 30 to $90 \mathrm{~V}, 200-400 \mu \mathrm{sec}$, delivered once every $30-60 \mathrm{sec}$. These parameters were varied to optimize IPSC amplitude and stability. The holding potential was $-50 \mathrm{mV}$.

For recording miniature IPSCs (mIPSCs), the potassium gluconate in the internal solution was replaced with $\mathrm{KCl}$ to invert the chloride gradient and allow for a more accurate measurement of these miniature events. Recording of mIPSCs was done using the same mixture of antagonist used in the evoked IPSC studies, with the addition of tetrodotoxin (TTX) $(1 \mu \mathrm{M})$. The holding potential was $-60 \mathrm{mV}$ for all mIPSC studies.

All compounds were typically made in a $1000 \times$ stock and diluted into the ACSF immediately before use. L-AP4 and DCPG was made daily; all other compounds were aliquoted and stored at $-20^{\circ} \mathrm{C}$. Compounds were applied to the bath using a three-way stopcock and were always applied for $10 \mathrm{~min}$ to achieve a plateau concentration.

\section{Reserpinization}

For both electrophysiological and behavioral studies, catecholamine depletion was achieved by a modification of our previous method (Witt- 
mann et al., 2002). Reserpine was prepared fresh each day and dissolved at $500 \mathrm{mg} / \mathrm{ml}$ in glacial acetic acid. Once fully solubilized, the volume was increased by drop-wise addition of prewarmed $37^{\circ} \mathrm{C}$ water with constant mixing to yield a final concentration of $5 \mathrm{mg} / \mathrm{ml}$. Rats were injected subcutaneously with a $5 \mathrm{mg} / \mathrm{kg}$ dose of reserpine $18-24 \mathrm{hr}$ before being used. Within $20 \mathrm{~min}$ of administration, this treatment induced a marked catalepsy in all animals. For electrophysiological studies, the tyrosine hydroxylase inhibitor $\alpha$-methyl-L-p-tyrosine $(0.1 \mathrm{~mm})$ was included in all solutions used for dissection and recording to maintain a dopaminedepleted state after slicing.

\section{Behavioral studies}

Animals. For behavioral studies, all experiments were performed on male Sprague Dawley rats (Taconic Farms) weighing 250-350 gm. All experiments were performed during the light cycle (6 A.M.-6 P.M.). Third ventricle cannulated (TVC) rats (Taconic Farms) had guide cannula implanted such that subsequent placement of an injection cannula allowed for infusion into the third ventricle. These rats were used in haloperidolinduced catalepsy and reserpine-induced akinesia studies. For chronic striatal dopamine depletion studies, rats lesioned by unilateral injection of 6-OHDA into the medial forebrain bundle, and prescreened for apomorphine-induced contralateral rotation, were purchased from Taconic Farms. For third ventricle intracerebroventricular injection of L-AP4, unilateral lesioned rats were cannulated within 1 week after arrival to the facility. Unilateral lesioned rats were anesthetized with sodium pentobarbital ( $60 \mathrm{mg} / \mathrm{kg}$, i.p.) and stereotaxically implanted with a stainless steel guide cannula positioned $2 \mathrm{~mm}$ above the third ventricle (4.3 $\mathrm{mm}$ posterior, $0 \mathrm{~mm}$ lateral, and $3.7 \mathrm{~mm}$ ventral to bregma) according to the rat brain atlas of Paxinos and Watson (1998). Rats were allowed to recover from TVC surgery for a minimum of $7 \mathrm{~d}$ before testing.

Induction and measurement of catalepsy. Catalepsy was assessed using a rectangular wire grid positioned at an $\sim 75^{\circ}$ angle to the testing surface. For each test a rat was positioned gently on the grid, and the time spent on the grid before the first complete relocation of the forepaws on the grid was measured (maximum duration, $150 \mathrm{sec}$ ) (Rodriguez et al., 2001). TVC rats, randomly assigned to treatment groups, were injected with haloperidol ( $1.5 \mathrm{mg} / \mathrm{kg}$, i.p., dissolved in $0.2 \%$ lactic acid) and monitored for catalepsy $1.5 \mathrm{hr}$ later. Cataleptic rats were subsequently reexamined 10 min after intracerebroventricular administration of either L-AP4 (5$100 \mathrm{nmol} / 2 \mu \mathrm{l})$ or vehicle $(2 \mu \mathrm{l} \mathrm{PBS})$.

Induction and measurement of akinesia. TVC rats were injected with reserpine $(5 \mathrm{mg} / \mathrm{kg}$, s.c., dissolved in $1 \%$ acetic acid) and kept in their home cages for 1.5-2.0 hr after injection. Activity was measured by placing rats in photocell activity cages (Hamilton-Kinder, Poway, CA) equipped with $16 \times 16$ infrared beams. After a $30 \mathrm{~min}$ baseline period, rats were given a single intracerebroventricular injection of either L-AP4 ( $50 \mathrm{nmol} / 2 \mu \mathrm{l}$ ) or vehicle ( $2 \mu \mathrm{l} \mathrm{PBS}$ ), and motor activity was recorded for an additional $30 \mathrm{~min}$.

Measurement of forelimb asymmetry in unilateral 6-OHDA-lesioned rats. The cylinder test was used to assess forelimb asymmetry in unilateral dopamine-depleted rats as described previously (Schallert et al., 2000; Lundblad et al., 2002). For each test, rats were placed in a Plexiglas cylinder ( $20 \mathrm{~cm}$ diameter, $30 \mathrm{~cm}$ height), and rearing behavior was video recorded via a large mirror positioned at a $45^{\circ}$ angle directly below the base of the cylinder. Video recordings were subsequently analyzed for landing-associated events, and the number of ipsilateral, contralateral (affected limb), or both paw contacts was noted for the 10 min test period. Only supporting contacts of forepaws during a landing (with open digits to the cylinder base) were counted. Within $4 \mathrm{~d}$ of baseline testing, rats were placed into cylinders and immediately given a single intracerebroventricular injection of L-AP4 $(100 \mathrm{nmol} / 4 \mu \mathrm{l})$ and tested further for $10 \mathrm{~min}$. A separate group of lesioned rats was tested $30 \mathrm{~min}$ after injection of L-DOPA methyl ester $(6 \mathrm{mg} / \mathrm{kg}$, i.p.) combined with benserazide- $\mathrm{HCl}$ (DOPA decarboxylase inhibitor; $15 \mathrm{mg} / \mathrm{kg}$, i.p.).

\section{Statistical analysis}

For haloperidol-induced catalepsy studies, time on grid (seconds) after L-AP4 or vehicle treatment was expressed for each rat as a percentage of pretest value. Differences in mean percentage values among vehicle, 5 ,
50, and 100 nmol L-AP4-treated groups were compared by one-way ANOVA followed by Dunnett's post test to assess significance in comparison with vehicle-treated rats. For reserpine-induced akinesia studies, motor activity (beam breaks per 30-min period) after L-AP4 or vehicle treatment was expressed for each rat as a percentage increase of baseline values recorded from the same animal before treatment. Differences in percentage values between vehicle and L-AP4-treated groups were compared using a two-tailed unpaired $t$ test. For forelimb asymmetry studies, forelimb usage scores were calculated as a percentage by dividing the number of times a paw was used (ipsilateral to lesion, contralateral to lesion, or both paws simultaneously) by the total number of landings. Forelimb usage scores were then used to determine an overall forelimb asymmetry score [\% ipsilateral paw $-(\%$ contralateral paw $+\%$ both paws)] for each rat. In this way, a positive asymmetry score reflects preferential use of the forelimb ipsilateral to the lesion site, whereas negative scores or a score approaching 0 reflects a lack of ipsilateral bias relative to the use of the contralateral forelimb and simultaneous use of both forelimbs. Comparisons of asymmetry scores were made using repeatedmeasures two-factor ANOVA, in which treatment (before versus after drug; within factor) and drug (L-AP4 or L-DOPA; between factor) values were noted for each rat. Post hoc comparisons were performed using the Bonferroni test. Statistical significance was set at $p<0.05$ for all experiments. All data are expressed as mean \pm 1 SEM.

\section{Results}

\section{Activation of group III mGluRs modulates inhibitory transmission at the striatopallidal synapse}

To test the hypothesis that activation of group III mGluRs modulates transmission at the striatopallidal synapse, we used wholecell patch-clamp recordings from neurons in the GP. As described previously (Kita and Kitai, 1991; Nambu and Llinas, 1994; Cooper and Stanford, 2000), we observed a heterogeneous population of neurons that could be identified on the basis of differences in spike frequency adaptation, time-dependent inward rectification, and rebound spiking. We observed no significant differences among these populations in any of the studies described below and have therefore combined the results.

Stimulation of the striatum elicited outward IPSCs that have an $I-V$ relationship consistent with a $\mathrm{GABA}_{\mathrm{A}}$-mediated chloride flux (Fig. $1 A, B$ ) and were blocked by the $\mathrm{GABA}_{\mathrm{A}}$ antagonist bicuculline (pre-drug IPSC amplitude $=124.5 \pm 34.0 ; 20 \mu \mathrm{M}$ bicuculline $=15.2 \pm 7.6 \mathrm{pA} ; n=4 ; p<0.05$; paired $t$ test) (Fig. 1 ). Previous studies have shown that stimulation of the striatal input to the GP evokes $\mathrm{GABA}_{\mathrm{A}}$-mediated IPSCs that can be modulated by dopamine or the $\mathrm{D} 2$ selective agonist quinpirole. On the other hand, the local collateral inputs recorded under conditions that minimize the contribution of striatal inputs are insensitive to dopamine receptor activation (Cooper and Stanford, 2001). We used this selective modulation of the striatopallidal synapse as a method of confirming the striatal origin of IPSCs. Recording and stimulating under the conditions described in Materials and Methods produced an IPSC that was inhibited by activation of D2 dopamine receptors by a low dose of quinpirole (pre-drug $152.1 \pm 46.7 \mathrm{pA} ; 3 \mu \mathrm{M}$ quinpirole $119.4 \pm 37.6 \mathrm{pA}$; mean $\pm \mathrm{SEM}$; $p<0.05$; paired $t$ test; $n=4)$. We also performed studies in which we recorded from GP neurons in coronal slices and stimulated locally to preferentially activate local collateral inputs (Cooper and Stanford, 2001). Consistent with this previous report, $3 \mu \mathrm{M}$ quinpirole had no significant effect on transmission under these conditions (pre-drug $125.8 \pm 32.0 \mathrm{pA} ; 3 \mu \mathrm{M}$ quinpirole $117.3 \pm$ $28.1 \mathrm{pA}$; mean \pm SEM; $p>0.05$; paired $t$ test; $n=5$ ).

Application of the highly selective group III mGluR agonist L-AP4 (Evans et al., 1982; Bushell et al., 1995) produced a dosedependent inhibition of these IPSCs that reversed as the compound washed out of the bath (Fig. $2 A, B$ ). L-AP4 elicited a max- 


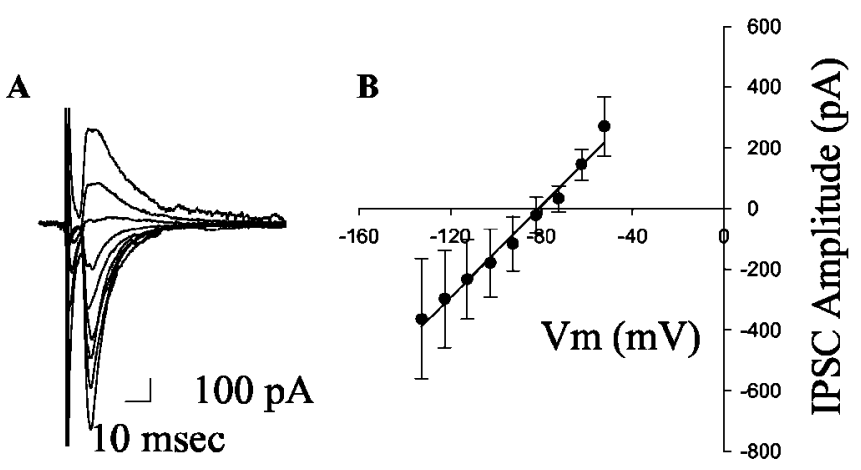

C

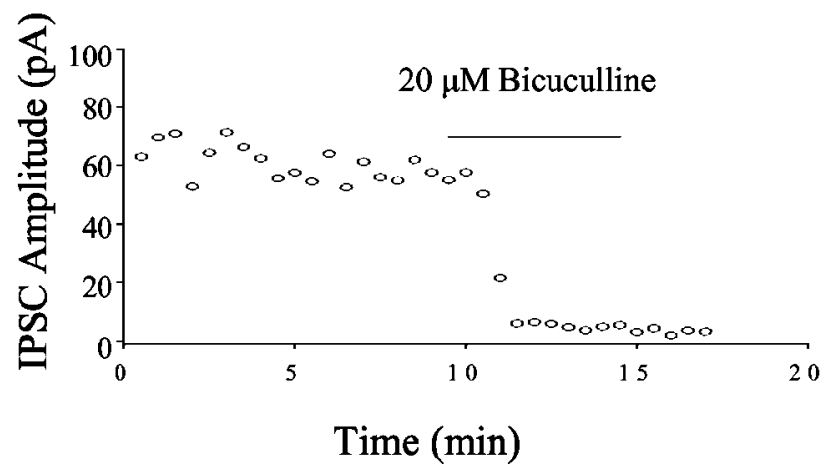

Figure 1. Characterization of striatopallidal IPSCS. IPSCS were evoked by stimulating the striatum as described in Materials and Methods. $A$, A representative set of traces demonstrating the voltage dependence of the IPSC. The peak current varied with voltage in a linear manner $(B)$ and had an average reversal potential of $-86 \pm 5 \mathrm{mV}$ (mean $\pm S E M ; n=4$ ), a value that compares well with the calculated chloride reversal potential of $-86 \mathrm{mV}$. Consistent with this, application of bicuculline ( $20 \mu \mathrm{M}$ ) produced a rapid and complete block of the IPSC ( $C$.

imal effect of $85.2 \%$ inhibition at $3 \mu \mathrm{M}$ (pre-drug $112.4 \pm 29.9$ $\mathrm{pA}$; mean \pm SEM; $3 \mu \mathrm{M} \mathrm{L}-\mathrm{AP} 416 \pm 4.6 \mathrm{pA} ; p=0.004$; paired $t$ test). The response to L-AP4 was biphasic, with L-AP4 eliciting a somewhat smaller inhibition of IPSCs at $10 \mu \mathrm{M}$, and a recovery of the effect at $30 \mu \mathrm{M}$ (Fig. 2C). L-AP4 exhibits potencies at recombinant rat group III mGluRs of $0.2-1 \mu \mathrm{M}$ at mGluR4, $0.6-0.9 \mu \mathrm{M}$ at mGluR6, 160-1300 $\mu \mathrm{M}$ at mGluR7, and 0.7-0.9 $\mu \mathrm{M}$ at mGluR8 (Schoepp et al., 1999). At other synapses in the indirect pathway, much high concentrations $(0.3-1 \mathrm{mM})$ of L-AP4 are required to produce a maximal effect (Awad-Granko and Conn, 2001; Wittmann et al., 2001). This is normally interpreted to suggest that mGluR7 mediates these actions, because millimolar concentrations of L-AP4 are required to activate this receptor (for review, see Schoepp et al., 1999). This suggests that the effect of low concentrations of L-AP4 on transmission at the striatopallidal synapse exhibiting an approximate $\mathrm{EC}_{50}$ in the $1-3 \mu \mathrm{m}$ range is mediated by a group III mGluR other than mGluR7. This effect may exhibit some desensitization at higher doses, which could explain the decrease in effect observed between 3 and $10 \mu \mathrm{M}$ L-AP4. At $30 \mu \mathrm{M}, \mathrm{L}-\mathrm{AP} 4$ may begin to activate mGluR7 and lead to an additional inhibition of transmission at this synapse.

Because mGluR6 is not expressed at significant levels in the CNS (Nakajima et al., 1993), this suggests that either mGluR4 or mGluR8 mediates the effects of low concentrations of L-AP4 at this synapse. To test for the involvement of mGluR8, we used the recently developed mGluR8-selective agonist DCPG. DCPG exhibits potencies at recombinant human group III mGluRs of 8.8 $\mu \mathrm{M}$ at mGluR4, $3.6 \mu \mathrm{M}$ at mGluR6, $>100 \mu \mathrm{M}$ at mGluR7, and 31 nM at mGluR8 (Thomas et al., 2001). Application of $300 \mathrm{~nm}$
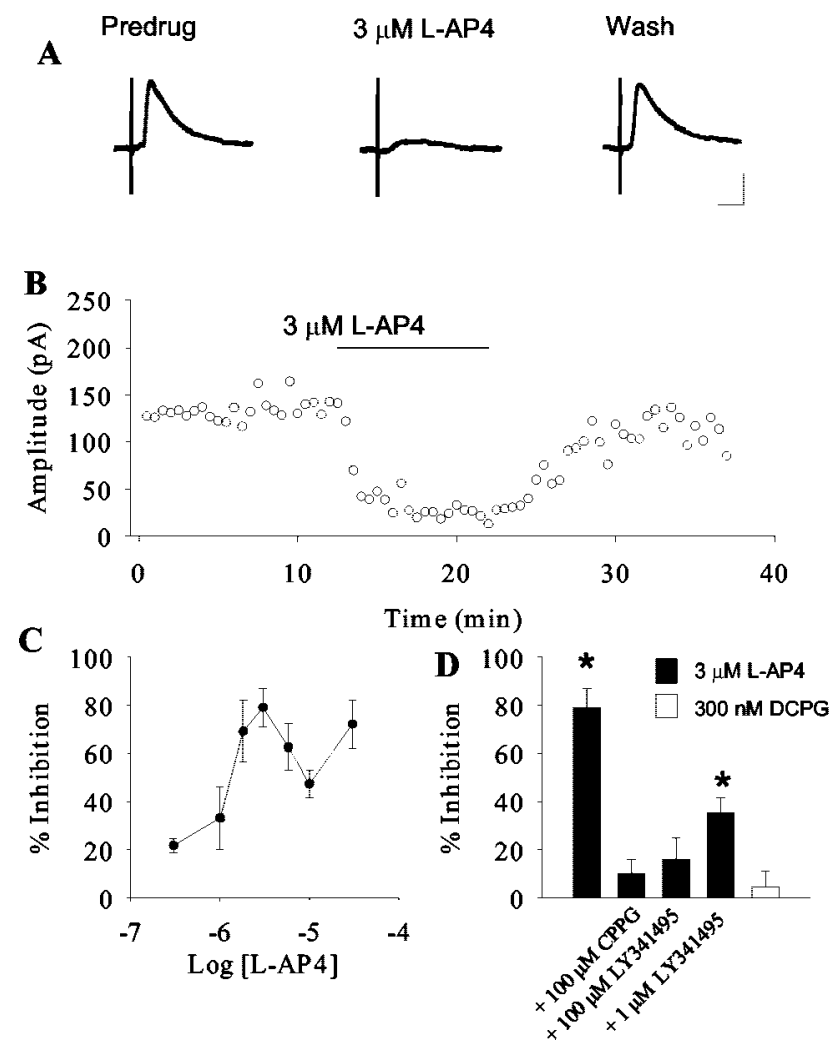

Figure 2. Activation of group III mGluRs inhibits striatopallidal transmission. Representative traces $(A)$ and time course $(B)$ demonstrating the inhibitory effect of $3 \mu \mathrm{M} \mathrm{L-AP4}$ on transmission at the striatopallidal synapse. $C$, The mean concentration-response relationship illustrating the dose-dependent nature of the L-AP4-induced modulation. The relationship is biphasic with a peak at $3 \mu \mathrm{M}$. Data represent the mean \pm SEM from 5-12 cells per point. D, Summary of antagonist studies demonstrating that the effect of L-AP4 is not significant in the presence of $100 \mu \mathrm{M}$ CPPG or $100 \mu \mathrm{m}$ LY341495. LY341495 (1 $\mu \mathrm{m}$ ) was less effective at blocking this response. The mGluR8 selective agonist DCPG does not mimic the effects of L-AP4. Data represent mean \pm SEM from five cells per condition. ${ }^{*} p<0.05$.

DCPG, a concentration 10-fold higher than the $\mathrm{EC}_{50}$ of this compound at recombinant mGluR8, produced no effect on transmission at the striatopallidal synapse (pre-drug $63.1 \pm 7.3 \mathrm{pA} ; 300$ nм DCPG $59.9 \pm 9$ pA; $p=0.3$; paired $t$ test) (Fig. $2 D$ ). This suggests that mGluR8 does not play a role in modulating transmission at this synapse.

Our previous anatomical studies suggest that within the GP, mGluR4 is predominately localized to inhibitory striatal terminals (Bradley et al., 1999). We therefore would expect that activation of this receptor would not produce a modulation of transmission at the local collateral synapse. We tested this hypothesis by recording from GP neurons in coronal slices as described above. Consistent with the anatomical localization of mGluR4, application of L-AP4 did not produce a significant modulation of transmission at these putative collateral synapses (pre-drug $106.4 \pm 27.5 \mathrm{pA} ; 3 \mu \mathrm{M} \mathrm{L}-\mathrm{AP} 488.2 \pm 32.4 \mathrm{pA}$; mean $\pm \mathrm{SEM} ; p>$ 0.05 ; paired $t$ test; $n=6$ ).

To characterize further the pharmacology of this response, we used available antagonists (Fig. $2 D$ ). Consistent with mediation by a group III mGluR, preapplication of $100 \mu \mathrm{M}$ CPPG, a group III mGluR-preferring antagonist (Toms et al., 1996), inhibited the response to L-AP4 (Fig. 3) (pre-drug $83.4 \pm 12.7$ pA; $3 \mu \mathrm{M}$ $\mathrm{L}-\mathrm{AP} 4+100 \mu \mathrm{M}$ CPPG $71.5 \pm 11.5 \mathrm{pA} ; p>0.05$; paired $t$ test). We found no evidence for an effect of CPPG alone on transmission at the striatopallidal synapse (pre-drug $147.0 \pm 68.6 \mathrm{pA} ; 100$ 
$\mathbf{A}$

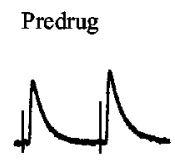

$10 \mu \mathrm{M}$ L-AP4

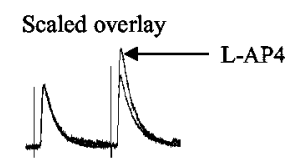

$\mathbf{B}$

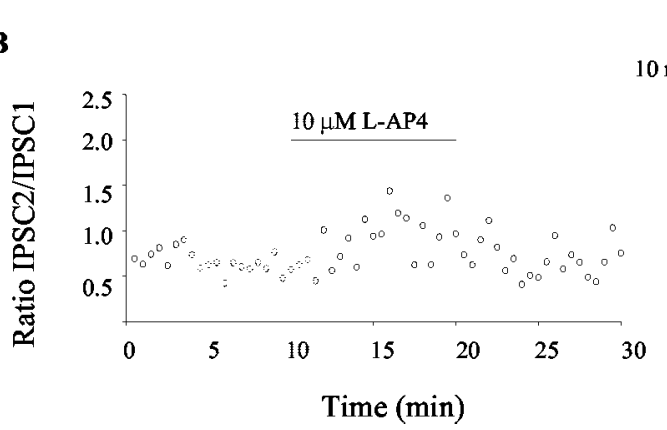

Figure 3. Application of L-AP4 alters paired-pulse plasticity. Representative traces $(A)$ and time course $(B)$ illustrate the effect of $\mathrm{L}-\mathrm{AP} 4$ on the paired-pulse ratio. The facilitation of potentiation observed in these studies is consistent with a presynaptic mechanism of action.

$\mu \mathrm{M}$ CPPG $171.2 \pm 87.0 \mathrm{pA}$; mean \pm SEM; $p>0.05$; paired $t$ test; $n=5)$, suggesting that the group III mGluRs are not activated by endogenous glutamate in the slice preparation. We also used the mGluR antagonist LY341495 (Kingston et al., 1998). LY341495 blocks all mGluRs at high concentrations. The $\mathrm{IC}_{50}$ values at recombinant group I and II mGluRs, as well as mGluR6, -7, and -8 are all below $5 \mu \mathrm{M}$, whereas the IC50 of this compound at mGluR4 is $25 \mu \mathrm{M}$ (Kingston et al., 1998; Schoepp et al., 1999). Interestingly, $100 \mu \mathrm{M}$ LY341495 was required to produce a complete block of L-AP4-induced inhibition of transmission at the striatopallidal synapse. Taken together with the potency of L-AP4 and the lack of effect of DCPG, these data suggest that the L-AP4 modulation of synaptic transmission is consistent with actions at mGluR4.

\section{The effect of L-AP4 at the striatopallidal synapse is mediated} by a presynaptic mechanism

Previous studies have shown that mGluR4 is presynaptically localized at the striatopallidal synapse (Bradley et al., 1999). Therefore, we would predict that the effect of L-AP4 on transmission at the striatopallidal synapse is mediated by a presynaptic mechanism. To test this hypothesis, we examined the effect of L-AP4 on paired-pulse plasticity and on TTX-resistant mIPSCs. Pairs of IPSCs were evoked by two stimuli of equal strength and duration, separated by an interstimulus interval of 50-100 msec. Under these conditions, the second IPSC was potentiated relative to the first. Consistent with a presynaptic mechanism of action (Zucker and Regehr, 2002), 3-10 $\mu \mathrm{M}$ L-AP4 induced an increase in the paired-pulse ratio (second IPSC/first IPSC) (Fig. 3) (pre-drug = $1.2 \pm 0.2 ; \mathrm{L}-\mathrm{AP} 4=1.9 \pm 0.2 ;$ mean $\pm \mathrm{SEM} ; p<0.05$; paired $t$ test; $n=7)$.

In the presence of $1 \mu \mathrm{M}$ TTX and using a modified internal solution (see Materials and Methods), inward mIPSCs were recorded from GP neurons. Application of $3 \mu \mathrm{M}$ L-AP4 induced a significant decrease in the frequency of mIPSC (pre-drug, $13.9 \pm$ $2.1 \mathrm{~Hz} ; 3 \mu \mathrm{M} \mathrm{L}-\mathrm{AP} 4 ; 9.0 \pm 2.0 \mathrm{~Hz}$; mean $\pm \mathrm{SEM} ; p<0.01$; paired $t$ test; $n=7$ ) without affecting mIPSC amplitude (pre-drug, $20.7 \pm 6.9 \mathrm{pA} ; 3 \mu \mathrm{M} \mathrm{L}-\mathrm{AP} 420.5 \pm 7.7 \mathrm{pA}$; mean $\pm \mathrm{SEM} ; p>0.05$; paired $t$ test; $n=7$ ) (Fig. 4), suggesting a presynaptic site of action. Taken together, these results suggest strongly that the L-AP4-induced modulation of transmission at the striatopallidal synapse is mediated by a presynaptic mechanism.
$\mathbf{A}$

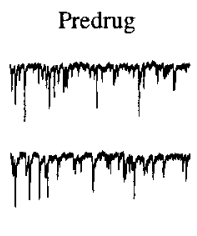

$3 \mu \mathrm{M}$ L-AP4
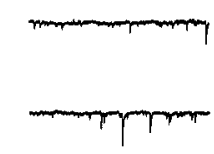

$\mathbf{B}$
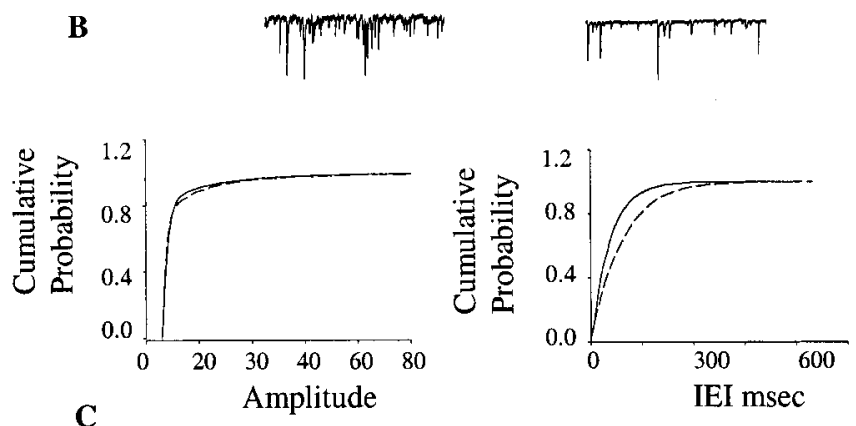

C
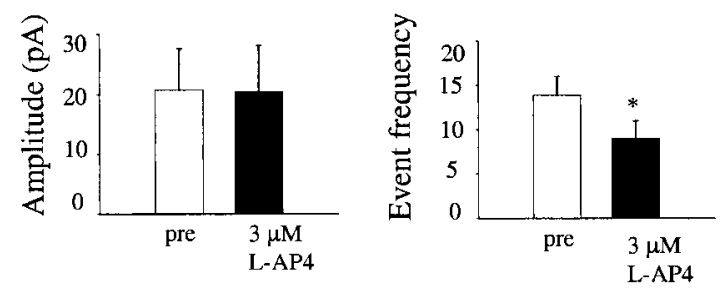

Figure 4. Application of L-AP4 decreases mIPSC frequency. A, Examples of mIPSCs before (left) and after (right) application of $3 \mu \mathrm{M} \mathrm{L}$-AP4. B, Cumulative histograms illustrating a lack of effect of L-AP4 on mIPSC amplitude, but a significant shift in the cumulative probability histogram of interevent intervals, suggesting a decrease in event frequency. C, Summary bar graph of data from seven experiments illustrating a significant effect of $3 \mu \mathrm{m} \mathrm{L}$-AP4 on mIPSC frequency. ${ }^{*} p<0.01 ; n=7$.

\section{L-AP4 does not inhibit striatopallidal transmission in mGluR4 knock-out mice}

Our studies suggest that a presynaptic group III mGluR with a pharmacological profile similar to mGluR4 mediates an inhibition of transmission at the striatopallidal synapse. These data in combination with previous anatomical studies are suggestive of mGluR4 playing the predominate role in this response; however, the available pharmacological tools are not highly selective. Therefore, to confirm that group III mGluR-mediated modulation of transmission at the striatopallidal synapse is caused by the activation of mGluR4, we performed studies in mGluR knockout mice. Studies in slices prepared from control 129X1/SvJ mice demonstrate a significant inhibition of transmission at the striatopallidal synapse produced by application of $3 \mu \mathrm{M} \mathrm{L}-\mathrm{AP} 4$ (predrug 93.6 $\pm 22.6 \mathrm{pA}$; L-AP4 $47.8 \pm 6.8 \mathrm{pA} ; p<0.05$; paired $t$ test; $n=4$ ) (Fig. $5 A, C$ ). Interestingly, the effect is absent in studies performed in slices made from mGluR4 knock-out mice (Gprcld; The Jackson Laboratory) (Pekhletski et al., 1996) (predrug 178.9 \pm 38.3; L-AP4 190.2 \pm 44 ; paired $t$ test; $p>0.05 ; n=$ 7) (Fig. $5 B, C$ ). It should be noted that although these studies provide evidence that mGluR4 modulates transmission at the striatopallidal synapse, we cannot rule out an alternative explanation such as the possibility that knockout of the mGluR4 gene leads to some functional alteration in mGluR8; however, these data combined with the pharmacological studies outlined above provide convincing evidence that the group III mGluR modulation of transmission at the striatopallidal synapse is mediated by activation of mGluR4. 

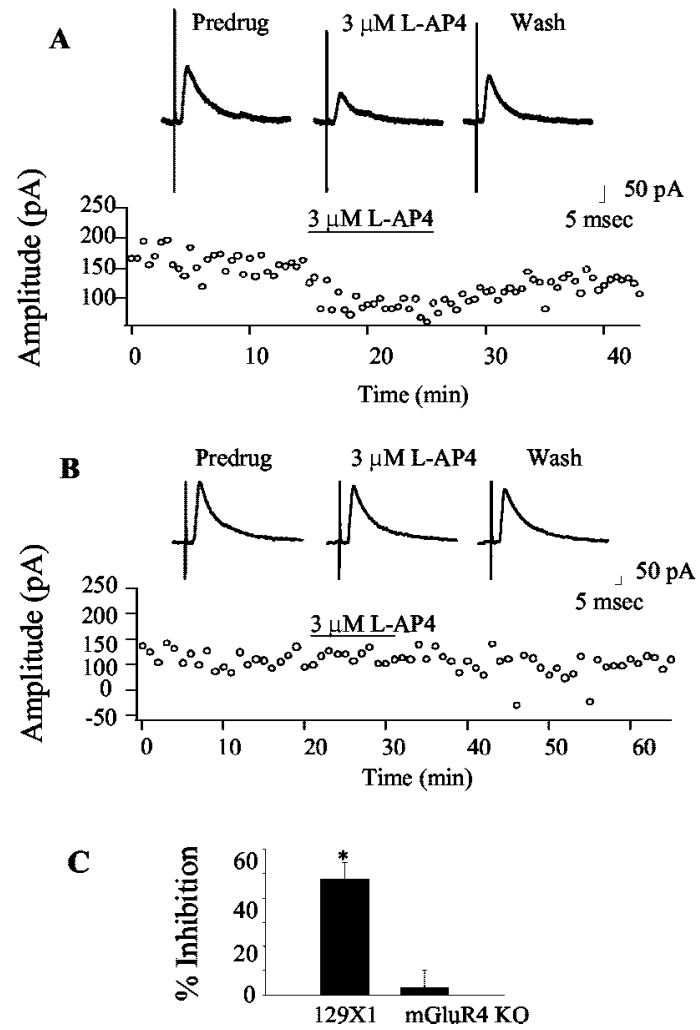

Figure 5. The L-AP4-induced inhibition of transmission at the striatopallidal synapse is absent in mGluR4 knock-out mice. A, Representative traces and time course of an experiment from wild-type 129X/SvJ mice illustrating the inhibitory effect of L-AP4 at their striatopallidal synapse. Interestingly, this effect is completely absent in mice lacking mGluR4 ( $B$ ), suggesting that this receptor underlies the group III mGluR-mediated modulation of transmission at the striatopallidal synapse. C, Summary graph representing mean \pm SEM data from control and knockout mice. * Significant effect of $\mathrm{L}-\mathrm{AP} 4, p<0.01 ; n=5$ cells per condition.

\section{The pharmacology of group III mGluR-mediated inhibition} of transmission at the striatopallidal synapse is not altered by overnight reserpine treatment

Our previous studies have demonstrated that dopamine depletion can induce a pronounced plasticity in mGluR pharmacology in other BG nuclei (Marino et al., 2002b; Wittmann et al., 2002). At the STN-SNr synapse, DA depletion by reserpinization produces a marked decrease in the ability of group II mGluR agonists to inhibit excitatory transmission and also in the ability of group III mGluR agonist to decrease inhibitory transmission (Wittmann et al., 2002). Furthermore, overnight treatment with haloperidol dramatically alters the pharmacology of group I mGluRmediated depolarization in both the STN and the SNr (Marino et al., 2002b). If dopamine depletion reduces the ability of mGluR4 to inhibit transmission at the striatopallidal synapse, this could reduce any potential antiparkinsonian effects of mGluR4 agonists. To determine the effect of L-AP4 on transmission at the striatopallidal synapse in dopamine-depleted animals, we used an overnight catecholamine depletion model. Rats 26-30 d old were treated with reserpine, and brain slices were prepared. Consistent with the observation in normal rats, application of $3 \mu \mathrm{M} \mathrm{L}-\mathrm{AP} 4$ produced a marked and reversible reduction in transmission at the striatopallidal synapse in slices from reserpinized animals (Fig. 6) $(\%$ inhibition $=48.8 \pm 5.8$ mean \pm SEM $)$. Although this effect of L-AP4 in slices from reserpinized animals was significantly smaller that that observed in slices from normal rats (control \% inhibition by $3 \mu \mathrm{M} \mathrm{L}-\mathrm{AP} 4=70.5 \pm 9.8 \%$; mean $\pm \mathrm{SEM} ; t$

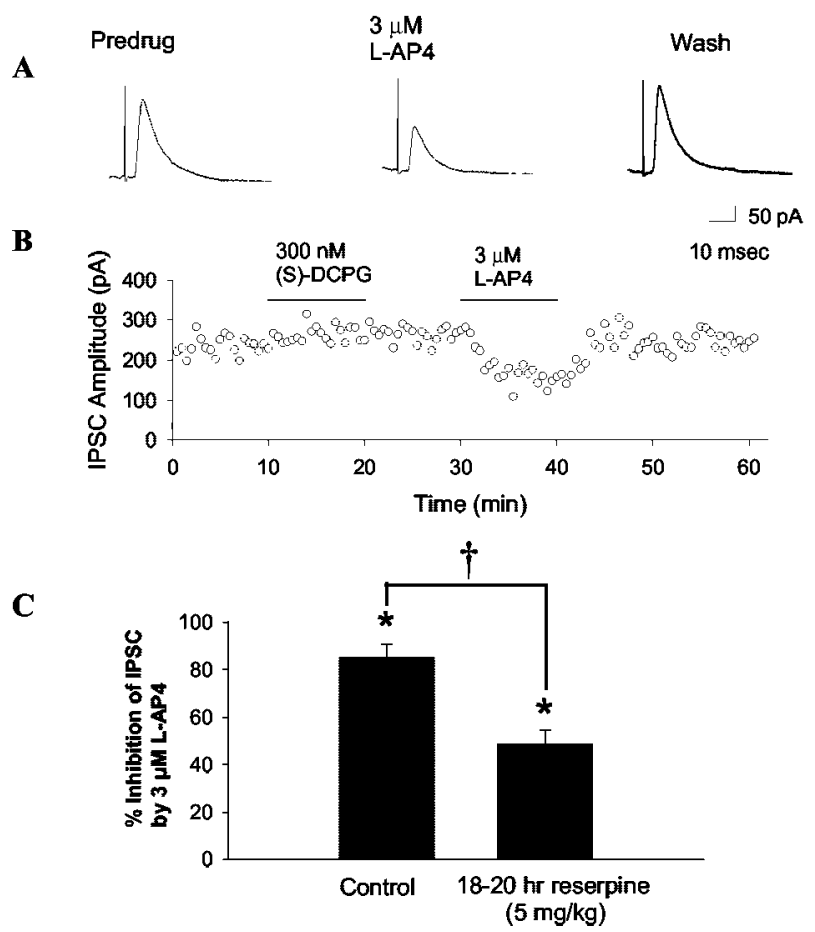

Figure 6. Activation of group III mGluRs inhibits striatopallidal transmission in reserpinized animals. Shown are representative traces $(A)$ and time course $(B)$ of the effects of group III agonists on striatopallidal transmission in slices from animals that received an $18-20 \mathrm{hr}$ reserpine treatment. C, Summary data illustrating the effect of reserpine treatment on L-AP4induced inhibition of transmission at the striatopallidal synapse. Although the effect of L-AP4 was significantly smaller in slices from reserpinized animals $\left({ }^{\dagger} p<0.01 ; n=4-7\right.$; $t$ test corrected for planned multiple comparisons), it was still highly significant ( ${ }^{*}$ significant effect of L-AP4, $p<0.01 ; n=4-7 ; t$ test corrected for planned multiple comparisons).

test; $p<0.01 ; n=4-7)$, the overall effect of L-AP4 was still significant (pre-drug $172.8 \pm 53$ pA; $3 \mu \mathrm{M} \mathrm{L}-\mathrm{AP} 497.3 \pm 36.9 \mathrm{pA}$; mean \pm SEM; paired $t$ test; $p<0.01 ; n=4$ ) In contrast, there was no evidence for a reserpine-induced change in DCPG sensitivity (control \% inhibition by $300 \mathrm{nM} \mathrm{DCPG}=5.2 \pm 5.9 \%$; reserpine $\%$ inhibition by $300 \mathrm{nM} \mathrm{DCPG}=4.4 \pm 6.4$; mean \pm SEM; $t$ test; $p>0.05 ; n=5-6)$.

\section{Activation of group III mGluRs produces antiparkinsonian actions in rodent models}

We have shown that activation of mGluR4 decreases inhibitory transmission at the striatopallidal synapse. According to the current model of information flow through the BG, this effect would be expected to yield an antiparkinsonian action in behavioral models of PD. We therefore tested for the ability of L-AP4 to reverse motor deficits in both acute and chronic rodent models of PD. The dopamine antagonist haloperidol was administered at a dose previously demonstrated to elicit an acute cataleptic response in rats (Wadenberg et al., 2001). Before test compound measurements, the level of haloperidol-induced catalepsy (mean \pm SEM in seconds) for rats preassigned to vehicle (130 \pm $13 \mathrm{sec}), 5 \mathrm{nmol}$ (141 $\pm 7 \mathrm{sec}), 50 \mathrm{nmol}(126 \pm 15 \mathrm{sec})$, and 100 $\mathrm{nmol}(127 \pm 14 \mathrm{sec}) \mathrm{L}-\mathrm{AP} 4$ treatment groups were $\operatorname{similar}(p=$ $0.89)$. L-AP4 dose-dependently reduced catalepsy scores $\left(F_{(3,16)}\right.$ $=9.94 ; p<0.001)$, producing a 57\% (50 nmol; $p<0.01)$ and $77 \%$ (100 nmol; $p<0.01$ ) improvement compared with vehicletreated animals (Fig. 7A). No significant difference between 50 and $100 \mathrm{nmol} \mathrm{L}-\mathrm{AP} 4$ was observed in this study. A second acute model of dopamine depletion, reserpine-induced akinesia, was 
A

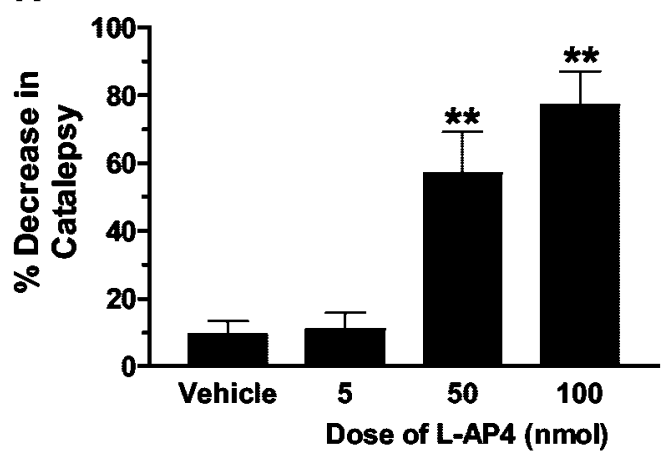

B
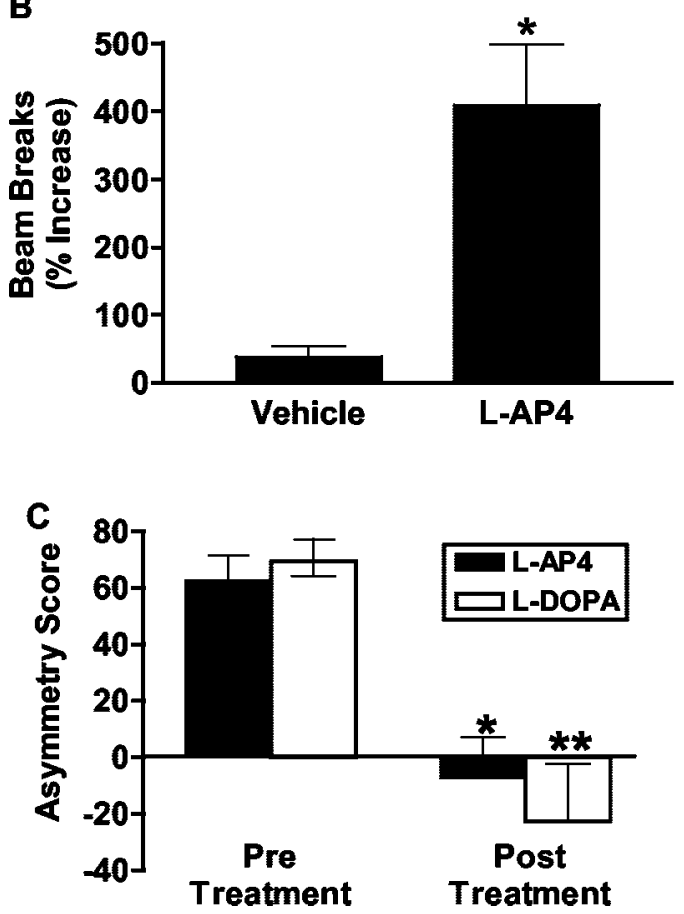

Figure 7. Activation of group III mGluRs produces antiparkinsonian actions in both acute and chronic rodent models of $\mathrm{PD}$. $A$, Effects of vehicle (PBS, intracerebroventricular) and increasing doses of L-AP4 (5, 50, and $100 \mathrm{nmol}$, i.c.v.) on haloperidol-treated rats ( $n=4-7$ animals per group). Catalepsy was measured using a rectangular vertical grid. ${ }^{* *} p<0.01$ compared with vehicle group. B, Effects of L-AP4 ( $50 \mathrm{nmol}$, i.c.v.) and vehicle (PBS, intracerebroventricular) on reserpine-treated rats ( $n=4-7$ animals per group). ${ }^{*} p<0.05$ compared with vehicle group. C, Effects of L-AP4 (100 nmol, i.c.v.) and L-DOPA (6 mg/kg, i.p.) on forelimb asymmetry in unilateral 6-OHDA-lesioned rats ( $n=4$ animals per group). Asymmetry score $=[\%$ ipsilateral paw $-(\%$ contralateral paw $+\%$ both paws $)]$. Positive asymmetry scores reflect preferential use of the forelimb ipsilateral to the lesion site. Negative asymmetry scores, or scores approaching zero, reflect a lack of ipsilateral bias relative to the use of the contralateral forelimb or simultaneous use of both forelimbs. ${ }^{*} p<0.05(\mathrm{~L}-\mathrm{AP} 4) ;{ }^{* *} p<0.01$ (L-DOPA), compared with corresponding pretreatment groups.

also used. When administered to reserpine-treated rats (Fig. $7 B$ ), $50 \mathrm{nmol}$ of L-AP4 produced a significant increase in activity compared with the vehicle-treated group $\left(t_{(9)}=2.9 ; p=0.02\right)$. These studies suggest that activation of group III mGluRs produced significant antiparkinsonian action in acute dopamine depletion models of this disease.

Because PD is a chronic condition that is associated with significant plasticity, we also studied unilateral 6-OHDA-lesioned rats to determine whether group III mGluR activation could improve the forelimb asymmetry observed in this chronic striatal dopamine depletion model. The cylinder test used in this study assesses a rat's independent forelimb use as it lands on the base of a cylindrical enclosure after rearing. For example, rats with severe unilateral dopamine depletion (as previously determined by apomorphine-induced contralateral rotational behavior) will preferentially use their nonaffected (ipsilateral) forepaw on landings after a rearing event and hence show a high asymmetry score (Lundblad et al., 2002). A potential anti-PD drug is expected to significantly lower the forelimb asymmetry score in these animals by increasing the contralateral (affected) forelimb use [either independently of, or in tandem with (both), the ipsilateral forelimb]. For 6-OHDA-lesioned rats, the proportion of landings performed by the ipsilateral forepaw amounted to $>60 \%$ of total landings in both pretreatment groups (Fig. 7C). There was no significant difference between pretreatment asymmetry scores for the two groups (Fig. $7 C)(p=0.44)$. As depicted in Figure 7, both L-AP4 and L-DOPA significantly decreased forelimb asymmetry scores compared with pretreatment groups as reflected by a significant treatment (pre versus post) effect $\left(F_{(1,6)}=39.05 ; p<\right.$ $0.001)$. Furthermore, L-AP4 was as efficacious as the prototypical anti-PD drug L-DOPA, as suggested by a lack of drug effect or drug by treatment interaction. Post hoc analysis confirmed that both L-AP4 and L-DOPA significantly reduced asymmetry scores relative to pretreatment baseline scores (Fig. 7C).

\section{Discussion}

In the present study we have found that the activation of group III mGluRs inhibits transmission at the striatopallidal synapse. This effect is mediated by a presynaptic mechanism of action, and its pharmacology is consistent with the activation of mGluR4. On the basis of the anatomical distribution of the group III mGluRs in the BG and the lack of effect observed in slices from mGluR4 knock-out mice, we conclude that activation of mGluR4 presynaptically localized on striatopallidal terminals decreases inhibitory transmission at the striatopallidal synapse. Consistent with this, and with the current models of the role of the GP in the pathophysiology of $\mathrm{PD}$, we have found that intracerebroventricular injection of L-AP4 has antiparkinsonian actions in both acute and chronic rat models of the disease.

Previous studies have found that intracerebroventricular injection of a selective A2a adenosine receptor agonist produced behavioral effects in the 6-OHDA rat model of PD (Koga et al., 2000) that are likely mediated at the striatopallidal synapse. Furthermore, studies of the distribution of radiolabeled compounds injected into the third ventricle suggest that this method results in diffusion to the GP (Fenstermacher and Davson, 1982; GhersiEgea et al., 1996). Therefore, it is likely that intracerebroventricular-injected L-AP4 reaches the GP; however, at the concentrations used for intracerebroventricular injection in our behavioral studies, it is highly unlikely that this compound achieved concentrations sufficient to activate mGluR7. Therefore, only mGluR4 or mGluR8 are likely to mediate this effect. Our previous electrophysiological studies at other key synapses in the indirect pathway failed to find substantial evidence for a highpotency L-AP4-induced effect (Awad-Granko and Conn, 2001; Wittmann et al., 2001). This, coupled with our previous anatomical studies demonstrating that mGluR4 protein is localized presynaptically at striatopallidal synapses (Bradley et al., 1999), suggests that the striatopallidal synapse is unique within the indirect pathway in respect to group III mGluR pharmacology; however, the recent demonstration of mGluR4 immunoreactivity presynaptically localized to both inhibitory and excitatory terminals in the substantia nigra pars reticulata (Corti et al., 2002) raises the possibility that inputs that were not investigated in 
previous electrophysiological studies such as neuromodulatory inputs from the raphe or the pedunculopontine nucleus may also be modulated by mGluR4. Furthermore, it is important to note that other potential sites outside of the indirect pathway such as the cortex, including cortical inputs to the striatum, or the thalamus cannot be ruled out. For example, it is known that activation of a high-potency group III mGluR modulates transmission at the corticostriatal synapse (Pisani et al., 1997).

It has been well established that activation of mGluRs localized presynaptically at GABAergic synapses can decrease inhibitory transmission (for review, see Schoepp, 2001); however, the predominate input to the GP is inhibitory, with sparse glutamatergic input from the STN (Shink and Smith, 1995). Interestingly, recent immunogold studies detailing the subsynaptic localization of other mGluRs at inhibitory synapses in the BG have found these receptors to be located very close to or in the active zone at symmetric synapses (for review, see Smith et al., 2001). It is possible that glutamate spillover from the relatively sparse glutamatergic input may be able to provide a potent inhibition of transmission at these synapses because of the spatial localization of the target receptors. The group III mGluR-mediated modulation of inhibitory synaptic transmission by glutamate spillover from neighboring synapses has been described previously (Mitchell and Silver, 2000; Semyanov and Kullmann, 2000); however, future studies will be needed to determine the conditions under which mGluR4 is activated by endogenous agonists at the striatopallidal synapse.

The marked antiparkinsonian actions observed in our behavioral studies suggest that mGluR4 may represent an exciting and novel target for the treatment of PD. The recent clinical studies on $\mathrm{A} 2 \mathrm{a}$ adenosine antagonists, agents that act at least in part by decreasing transmission at the striatopallidal synapse (Shindou et al., 2001), suggest that targeting this particular synapse may provide a viable approach to antiparkinsonian therapy. The limited clinical efficacy of the A2a antagonists (Hubble and Hauser, 2002; Sherzai et al., 2002) may be attributable to the fact that antagonists can only reduce transmission to some basal level that was present before activation of the excitatory A2a adenosine receptor. This is evident in the fact that application of A2a antagonists fail to significantly affect striatopallidal transmission in the in vitro slice preparation without the addition of an A2a adenosine receptor agonist (Shindou et al., 2001). Therefore, targeting mGluR4 with an agonist should provide a more efficacious inhibition of transmission at the striatopallidal synapse and may result in a more effective palliative therapy for the treatment of PD that bypasses many of the pitfalls associated with dopamine replacement therapy.

\section{References}

Awad-Granko H, Conn PJ (2001) Activation of groups I or III metabotropic glutamate receptors inhibits excitatory transmission in the rat subthalamic nucleus. Neuropharmacology 41:32-41.

Bergman H, Feingold A, Nini A, Raz A, Slovin H, Abeles M, Vaadia E (1998) Physiological aspects of information processing in the basal ganglia of normal and parkinsonian primates. Trends Neurosci 21:32-38.

Bradley SR, Standaert DG, Rhodes KJ, Rees HD, Testa CM, Levey AI, Conn PJ (1999) Immunohistochemical localization of subtype 4a metabotropic glutamate receptors in the rat and mouse basal ganglia. J Comp Neurol 407:33-46.

Brown P, Oliviero A, Mazzone P, Insola A, Tonali P, Di Lazzaro V (2001) Dopamine dependency of oscillations between subthalamic nucleus and pallidum in Parkinson's disease. J Neurosci 21:1033-1038.

Bushell TJ, Jane DE, Tse HW, Watkins JC, Davies CH, Garthwaite J, Collingridge GL (1995) Antagonism of the synaptic depressant actions of
L-AP4 in the lateral perforant path by MAP4. Neuropharmacology 34:239-241.

Cooper AJ, Stanford IM (2000) Electrophysiological and morphological characteristics of three subtypes of rat globus pallidus neurone in vitro. J Physiol (Lond) 527:291-304.

Cooper AJ, Stanford IM (2001) Dopamine D2 receptor mediated presynaptic inhibition of striatopallidal GABA(A) IPSCs in vitro. Neuropharmacology 41:62-71.

Corti C, Aldegheri L, Somogyi P, Ferraguti F (2002) Distribution and synaptic localisation of the metabotropic glutamate receptor 4 (mGluR4) in the rodent CNS. Neuroscience 110:403-420.

El Deredy W, Branston NM, Samuel M, Schrag A, Rothwell JC, Thomas DG, Quinn NP (2000) Firing patterns of pallidal cells in parkinsonian patients correlate with their pre-pallidotomy clinical scores. NeuroReport 11:3413-3418.

Evans RH, Francis AA, Jones AW, Smith DA, Watkins JC (1982) The effects of a series of omega-phosphonic alpha-carboxylic amino acids on electrically evoked and excitant amino acid-induced responses in isolated spinal cord preparations. Br J Pharmacol 75:65-75.

Fenstermacher JD, Davson H (1982) Distribution of two model amino acids from cerebrospinal fluid to brain and blood. Am J Physiol 242:F171-F180.

Georgopoulos AP, DeLong MR, Crutcher MD (1983) Relations between parameters of step-tracking movements and single cell discharge in the globus pallidus and subthalamic nucleus of the behaving monkey. J Neurosci 3:1586-1598.

Ghersi-Egea JF, Finnegan W, Chen JL, Fenstermacher JD (1996) Rapid distribution of intraventricularly administered sucrose into cerebrospinal fluid cisterns via subarachnoid velae in rat. Neuroscience 75:1271-1288.

Grondin R, Bedard PJ, Hadj TA, Gregoire L, Mori A, Kase H (1999) Antiparkinsonian effect of a new selective adenosine $\mathrm{A} 2 \mathrm{~A}$ receptor antagonist in MPTP-treated monkeys. Neurology 52:1673-1677.

Hubble JP, Hauser R (2002) A novel adenosine antagonist (KW-6002) as a treatment for advanced Parkinson's disease with motor complications. Am Acad Neurol Abstr 54:S21.001.

Kanda T, Jackson MJ, Smith LA, Pearce RK, Nakamura J, Kase H, Kuwana Y, Jenner P (2000) Combined use of the adenosine A(2A) antagonist KW6002 with L-DOPA or with selective D1 or D2 dopamine agonists increases antiparkinsonian activity but not dyskinesia in MPTP-treated monkeys. Exp Neurol 162:321-327.

Kingston AE, Ornstein PL, Wright RA, Johnson BG, Mayne NG, Burnett JP, Belagaje R, Wu S, Schoepp DD (1998) LY341495 is a nanomolar potent and selective antagonist of group II metabotropic glutamate receptors. Neuropharmacology 37:1-12.

Kita H, Kitai ST (1991) Intracellular study of rat globus pallidus neurons: membrane properties and responses to neostriatal, subthalamic and nigral stimulation. Brain Res 564:296-305.

Koga K, Kurokawa M, Ochi M, Nakamura J, Kuwana Y (2000) Adenosine $\mathrm{A}(2 \mathrm{~A})$ receptor antagonists KF17837 and KW-6002 potentiate rotation induced by dopaminergic drugs in hemi-Parkinsonian rats. Eur J Pharmacol 408:249-255.

Lozano A, Hutchison W, Kiss Z, Tasker R, Davis K, Dostrovsky J (1996) Methods for microelectrode-guided posteroventral pallidotomy. J Neurosurg 84:194-202.

Lundblad M, Andersson M, Winkler C, Kirik D, Wierup N, Cenci MA (2002) Pharmacological validation of behavioural measures of akinesia and dyskinesia in a rat model of Parkinson's disease. Eur J Neurosci 15:120-132.

Magnin M, Morel A, Jeanmonod D (2000) Single-unit analysis of the pallidum, thalamus and subthalamic nucleus in parkinsonian patients. Neuroscience 96:549-564.

Maneuf YP, Mitchell IJ, Crossman AR, Brotchie JM (1994) On the role of enkephalin cotransmission in the GABAergic striatal efferents to the globus pallidus. Exp Neurol 125:65-71.

Marino MJ, Wittman M, Bradley SR, Hubert GW, Smith Y, Conn PJ (2001) Activation of group I metabotropic glutamate receptors produces a direct excitation and disinhibition of GABAergic projection neurons in the substantia nigra pars reticulata. J Neurosci 21:7001-7012.

Marino MJ, Awad H, Poisik O, Wittmann M, Conn PJ (2002a) Localization and physiological roles of metabotropic glutamate receptors in the direct and indirect pathways of the basal ganglia. Amino Acids 23:185-191.

Marino MJ, Awad-Granko H, Ciombor KJ, Conn PJ (2002b) Haloperidolinduced alteration in the physiological actions of group I mGlus in the 
subthalamic nucleus and the substantia nigra pars reticulata. Neuropharmacology 43:147-159.

Mink JW, Thach WT (1991) Basal ganglia motor control. I. Nonexclusive relation of pallidal discharge to five movement modes. J Neurophysiol 65:273-300.

Mitchell SJ, Silver RA (2000) Glutamate spillover suppresses inhibition by activating presynaptic mGluRs. Nature 404:498-502.

Nakajima Y, Iwakabe H, Akazawa C, Nawa H, Shigemoto R, Mizuno N, Nakanishi S (1993) Molecular characterization of a novel retinal metabotropic glutamate receptor mGluR6 with a high agonist selectivity for L-2-amino-4-phosphonobutyrate. J Biol Chem 268:11868-11873.

Nambu A, Llinas R (1994) Electrophysiology of globus pallidus neurons in vitro. J Neurophysiol 72:1127-1139.

Nambu A, Yoshida S, Jinnai K (1990) Discharge patterns of pallidal neurons with input from various cortical areas during movement in the monkey. Brain Res 519:183-191.

Nini A, Feingold A, Slovin H, Bergman H (1995) Neurons in the globus pallidus do not show correlated activity in the normal monkey, but phaselocked oscillations appear in the MPTP model of parkinsonism. J Neurophysiol 74:1800-1805.

Paxinos G, Watson C (1998) The rat brain in stereotaxic coordinates. New York: Academic.

Pekhletski R, Gerlai R, Overstreet LS, Huang XP, Agopyan N, Slater NT, Abramow Newerly W, Roder JC, Hampson DR (1996) Impaired cerebellar synaptic plasticity and motor performance in mice lacking the mGluR4 subtype of metabotropic glutamate receptor. J Neurosci 16:6364-6373.

Pisani A, Calabresi P, Centonze D, Bernardi G (1997) Activation of group III metabotropic glutamate receptors depresses glutamatergic transmission at corticostriatal synapse. Neuropharmacology 36:845-851.

Pycock C, Horton RW, Marsden CD (1976) The behavioural effects of manipulating GABA function in the globus pallidus. Brain Res 116:353-359.

Raz A, Vaadia E, Bergman H (2000) Firing patterns and correlations of spontaneous discharge of pallidal neurons in the normal and the tremulous 1-methyl-4-phenyl-1,2,3,6-tetrahydropyridine vervet model of parkinsonism. J Neurosci 20:8559-8571.

Rodriguez DM, Abdala P, Barroso-Chinea P, Obeso J, Gonzalez-Hernandez T (2001) Motor behavioural changes after intracerebroventricular injection of 6-hydroxydopamine in the rat: an animal model of Parkinson's disease. Behav Brain Res 122:79-92.

Rouse ST, Marino MJ, Bradley SR, Awad H, Wittmann M, Conn PJ (2000) Distribution and roles of metabotropic glutamate receptors in the basal ganglia motor circuit: implications for treatment of Parkinson's disease and related disorders. Pharmacol Ther 88:427-435.

Schallert T, Fleming SM, Leasure JL, Tillerson JL, Bland ST (2000) CNS plasticity and assessment of forelimb sensorimotor outcome in unilateral rat models of stroke, cortical ablation, parkinsonism and spinal cord injury. Neuropharmacology 39:777-787.

Schoepp DD (2001) Unveiling the functions of presynaptic metabotropic glutamate receptors in the central nervous system. J Pharmacol Exp Ther 299:12-20.

Schoepp DD, Jane DE, Monn JA (1999) Pharmacological agents acting at subtypes of metabotropic glutamate receptors. Neuropharmacology 38:1431-1476.

Semyanov A, Kullmann DM (2000) Modulation of GABAergic signaling among interneurons by metabotropic glutamate receptors. Neuron 25:663-672.

Sherzai A, Bara-Jimenez W, Gillespie M, Favit A, Bibbiani F, Morris MJ, Mouradian MM, Chase TN (2002) Adenosine A2a antagonist treatment of Parkinson's disease. Am Acad Neurol Abstr 54:P06.104.

Shindou T, Mori A, Kase H, Ichimura M (2001) Adenosine A(2A) receptor enhances GABA(A)-mediated IPSCs in the rat globus pallidus. J Physiol (Lond) 532:423-434.

Shink E, Smith Y (1995) Differential synaptic innervation of neurons in the internal and external segments of the globus pallidus by the GABA- and glutamate-containing terminals in the squirrel monkey. J Comp Neurol 358:119-141.

Shiozaki S, Ichikawa S, Nakamura J, Kitamura S, Yamada K, Kuwana Y (1999) Actions of adenosine A2A receptor antagonist KW-6002 on druginduced catalepsy and hypokinesia caused by reserpine or MPTP. Psychopharmacology 147:90-95.

Smith Y, Charara A, Paquet M, Kieval JZ, Pare J, Hanson JE, Hubert GW, Kuwajima M, Levey AI (2001) Ionotropic and metabotropic GABA and glutamate receptors in primate basal ganglia. J Chem Neuroanat 22:13-42.

Testa CM, Standaert DG, Young AB, Penney JB Jr (1994) Metabotropic glutamate receptor mRNA expression in the basal ganglia of the rat. J Neurosci 14:3005-3018.

Thomas NK, Wright RA, Howson PA, Kingston AE, Schoepp DD, Jane DE (2001) (S)-3,4-DCPG, a potent and selective mGlu8a receptor agonist, activates metabotropic glutamate receptors on primary afferent terminals in the neonatal rat spinal cord. Neuropharmacology 40:311-318.

Toms NJ, Jane DE, Kemp MC, Bedingfield JS, Roberts PJ (1996) The effects of $(R S)$-alpha-cyclopropyl-4-phosphonophenylglycine ((RS)-CPPG), a potent and selective metabotropic glutamate receptor antagonist. $\mathrm{Br} \mathrm{J}$ Pharmacol 119:851-854.

Wadenberg ML, Soliman A, VanderSpek SC, Kapur S (2001) Dopamine $\mathrm{D}(2)$ receptor occupancy is a common mechanism underlying animal models of antipsychotics and their clinical effects. Neuropsychopharmacology 25:633-641.

Wichmann T, DeLong MR (1997) Physiology of the basal ganglia and pathophysiology of movement disorders of basal ganglia origin. In: Movement disorders: neurological principals and practice (Watts RL, ed), pp 87-97. New York: McGraw-Hill.

Wichmann T, DeLong MR (1998) Models of basal ganglia function and pathophysiology of movement disorders. Neurosurg Clin N Am 9:223-236.

Wittmann M, Marino MJ, Bradley SR, Conn PJ (2001) Activation of group III mGluRs inhibits GABAergic and glutamatergic transmission in the substantia nigra pars reticulata. J Neurophysiol 85:1960-1968.

Wittmann M, Marino MJ, Conn PJ (2002) Dopamine modulates the function of group II and group III metabotropic glutamate receptors in the substantia nigra pars reticulata. J Pharmacol Exp Ther 302:433-441.

Zucker RS, Regehr WG (2002) Short-term synaptic plasticity. Annu Rev Physiol 64:355-405. 